\title{
Multilinear Isotropic and Multilinear Kinematic Hardening on AZ31 Magnesium Alloy
}

\author{
Venkata Sai Prashanth Sudula
}

\begin{abstract}
Magnesium and its alloys are turning out to be increasingly more utilized in the aviation and automobile industry due to its low weight. The technology has endured numerous enhancements enabling magnesium alloys to have a mechanical performance close to aluminium alloys and prevention from corrosion. This enables numerous potential applications for magnesium alloys subjected to multiaxial fatigue. To perform the plastic deformation on AZ31 alloy, we have utilised two techniques of multilinear hardening methods. i) isotropic hardening, ii) Kinematic hardening. To come up with an accurate result, we leveraged ANSYS software to perform the simulation with accuracy and precision. on arriving to the conclusion our goal towards analysing the multilinear properties of the AZ31 alloy with two mesh size 0.4 and $0.6 \mathrm{~mm}$.

Keywords: Engineering Alloys, Mechanical Properties, Al-Mg Alloys, Az31 Mechanical Properties, Multilinear Isotropic Hardening, Multilinear Kinematic Hardening Curves, Linear Element, And Quadratic Element Type.
\end{abstract}

\section{INTRODUCTION}

Aluminium alloys are of incredible technological significance, specifically for the ground transport networks. At the point when high quality, great erosion resistance, and high durability are required related to good formability and weldability, aluminium alloys with $\mathrm{Mg}$ and $\mathrm{Si}$ as alloying components are utilized. The comparison of practical and theoretical outcomes under the multilinear hardening of the aluminium alloys has a significant purpose to pick which material would be good to a specific end.

A few techniques to analyse multilinear hardening have been created over the most recent forty years and basically, because of the changes in the direction and the ratio which is caused due to the principle stress, old methodologies are not generally moderate under multiaxial loads.

Thus, in the most recent decades, a few multilinear hardening methods dependent on a critical plane and furthermore on vital, invariant, and vitality approaches have been proposed. In this paper have used multilinear hardening curves toanalyse the cyclic behaviours of the AZ31 alloy.

AZ31 alloy reacts differently for tensile and compression load tests in both monotonic and cyclic loading conditions. Under cyclic loading with stress and strain along vertical axis vis-a -vis equivalent plastic strain on horizontal axis, it is possible to understand the behaviour of the alloy and measure the fatigue failure in the alloy.

Manuscript received on June 09, 2021.

Revised Manuscript received on June 12, 2021.

Manuscript published on June 30, 2021.

* Correspondence Author

Venkata Sai Prashanth Sudula*, Graduate Student, Department of Mechanical Engineering, Federation UniversityAustralia, Ballarat, Australia. E-mail: venkatasaiprashanthsudula@gmail.com

(C) The Authors. Published by Blue Eyes Intelligence Engineering and Sciences Publication (BEIESP). This is an open access article under the CC BY-NC-ND license (http://creativecommons.org/licenses/by-nc-nd/4.0/)
During the processing of material under tensile load, deformation in material occurs. There are also possibilities of material failure in tensile loading condition.

In this paper, plasticity of magnesium alloy using multilinear isotropic and multi-linear kinematic hardening properties and the behaviour of the alloy under cycle load condition using Finite Element method are discussed. Finite Element analysis will be carried out with ANSYS software to analyse the results. Finite element method can yield accurate results by reducing manual calculations. Static structural analysis can be done by performing the tensile test, compression, torsional tests, etc., to obtain maximum stress, strain, von-mises, plastic strain, elastic strain, safety factor, and fatigue results.Eight simulations are performed in this paper, two simulations are performed in each of the categories namelymulti-linear isotropic hardening, and multi-linear kinematic hardening properties. Moreover, in each of the mentioned categories, two simulations with linear element with mesh size $0.4 \mathrm{~mm}$ and $0.6 \mathrm{~mm}$ and two other simulations with quadratic element with mesh size $0.4 \mathrm{~mm}$ and $0.6 \mathrm{~mm}$ are performed. In this simulation a cyclic loading is applied to specimen with change in displacement from $0-7.5 \mathrm{~mm}$

\section{LITERATURE REVIEW}

\section{Types of AZ Alloys}

$\mathrm{J}$ Bholen [1] has explained that AZ alloy is the development of $\mathrm{Mg}$ alloys which contains $\mathrm{Al}$ and $\mathrm{Zn}$ with $\mathrm{Al}$ having the highest rate of fixation. The similar compounds that can be obtained from this alloy are AZ31, AZ61, AZ80 and AZ91. The AZ compound is formed from the series of arrangement of aluminium and Zinc by combining their chemical numbers. The AZ alloy in the $\mathrm{AZ}$ arrangement is highly preferred in the application of cast and fashioned application which results in great cast ability and possess profound mechanical properties. Al complexion in the AZ alloy enables the development of the $\beta$-Mg17Al12 stage and the measurement of the developed compound is influenced from the deformability condition of the surface of development [10].The author states that high Al compound allows the series of the $\mathrm{Al}$ combinations of the Mg17Al12, and weakens the basal surface by opposing the development of indistinguishable limits and blocking formability. AZ combinations with high $\mathrm{Al}$ complexion are, therefore, most favoured for constructional applications.

The formability of these compounds appeared at the closest scale of alloying constituents, particularly increments of different rare elements (RE). [2] revealed that smaller scale alloying increases Ca and Ce in AZ31 alloys resulting in a slight improvement in formability.

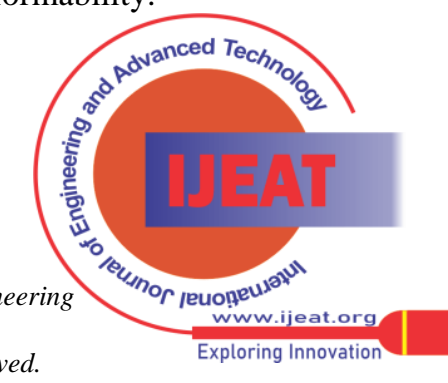


Grain refinement was observed to scale up with increment in merging alloy combinations which comes in good quality. He also stated that an improvement in rollability and expanded performance of non-basal slip planes and surface changes when AZ31 combinations were adjusted with $\mathrm{Li}$ alloying growth. Du, Zheng et al. announced the development of mechanical properties (extreme elasticity, yield quality, and extension) of AZ80 $\mathrm{Mg}$ composites with the expansion of Sn (Du et al., 2016). The composites with low convergences of $\mathrm{Sn}(<2 \%)$ have the best mix of properties after heat treatment.

\section{Cyclic Behaviour of AZ31 alloy}

AZ31 alloys are exceptionally alluring for light-weight developments due to the generally high solidarity to thickness proportions. Till recently, the greater part of the material is utilized for segments like mobile phones, gears, or clutches. Of late, there is an expanding request to utilize the material additionally, for consistently stacked basic parts and if conceivable, at higher assistance temperatures. To show the conduct of complex parts, for example by limited component technique, materials properties must be known. Cyclic lifetimes of the created compound AZ31 and the cast alloy AZ91 at room temperatures up to 300 degrees were researched and characterised. Harm parameters were resolved to portray the cyclic deformation behaviour [3]. The plastic strain amplitudes increase with increase in temperatures and when this happens repetitively cyclic lifetimes reduces. The increased temperature plastic strain amplitudes measure materials destruction during cyclic loading. The deforming behaviour of the two materials namely, AZ 31 and AZ 91 change from cyclic hardening to cyclic softening. As of now, at a temperature of 150 degrees Celsius, cyclic lifetimes of both compounds decreased and contrasted at the room temperature. Under pressurecontrolled stacking conditions, cyclic haul was seen at higher temperature. Cyclic behaviour prompts a difference in the deformation affecting the Coffin-Manson connection. Under the mean loading condition at a temperature, the negative mean pressure increases the cyclic lifetime and the positive mean pressure decreases the cyclic lifetime.

[4] has noted that the stress difference between monotonic and cyclic values is about $50 \mathrm{MPa}$ and for the compressive forces, this difference is about $20 \mathrm{MPa}$. Cyclic loading behaviour of materials along with monotonic behaviour of AZ31 reacts when a load is applied continuously. He further discussed von-misses results with tensile loading conditions and concluded that AZ31 magnesium alloy shows different behaviours under tensile and compression regime. At tension, it was observed that a cyclic hardening behaviour occurs (was verified a cyclic hardening) and at compression state, a slight softening behaviour was observed. From the below Figures1(a) and Figure1(b), [4] discussed $1 / 2$ strain cycle vs. axial strain when there is a change in strain percentage along with the variation of material when a cyclic and monotonic load is applied.

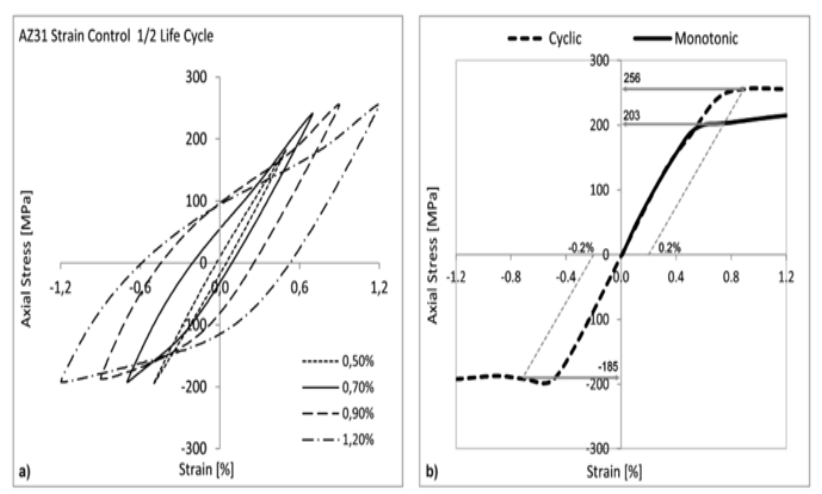

Figure 1. a \& b: Half fatigue life hysteresis loops and b) AZ31 monotonic and cyclic behaviour [4].

\section{Yield function}

According to Callister, the stress-strain behaviour of a material is defined as "the degree to which a structure deforms, or strains depend on the magnitude of an imposed stress" [8]. Most metals stressed in tension are relatively at low levels where stress and strain are proportional to each other. This is known as Hooke's law. Hooke's law can be used to calculate stress before yielding occurs. According to Matos, yield function is used to begin plastic deformation. This function describes the combinations of stresses that cause material to yield [9]. Matos has given the equation for von-mises criterion in Figure 2.

$$
\begin{aligned}
\text { yield function } & =Y_{F} \\
& =\sigma_{x}^{2}+\sigma_{y}^{2}+\sigma_{z}^{2}-\sigma_{x} \sigma_{y}-\sigma_{y} \sigma_{z}-\sigma_{z} \sigma_{x} \\
& +3\left(\tau_{x y}^{2}+\tau_{y z}^{2}+\tau_{z x}^{2}\right)=\sigma_{y i e l d}^{2}
\end{aligned}
$$

On the other hand [6], stated that plastic behaviour of homogenous isotropic materials is represented by a yield function.

Where as

$$
F\left(\sigma_{i j}\right)=f\left(\sigma_{i j}\right)-\sigma_{y}
$$

$f\left(\sigma_{i j}\right)=\sigma_{e}$ - equivalent stress, depends on stress strain contour

$\sigma_{y}-$ material yield parameter.

Yield function describes the surface in the stress space that demarks the stress between elastic and plastic behaviour of materials. This is called as yield surface.

There are three possible cases that stress state can occur.

- $F\left(\sigma_{i j}\right)<0$, the equivalent stress is lower than material yield $f\left(\sigma_{i j}\right)<\sigma_{y}$. The stress state at this point is inside the yield surface area with no plastic strain occurrence.

- $F\left(\sigma_{i j}\right)=0$ Plasticity condition equates the equivalent stress with material yield

- $f\left(\sigma_{i j}\right)=\sigma_{y}$. Stress point lies on the yield surface

- $F\left(\sigma_{i j}\right)>0$, plastic behaviour of material occurs.

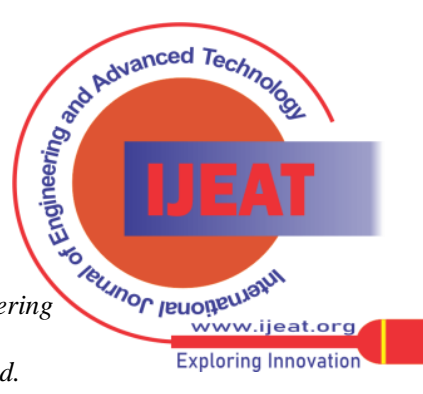




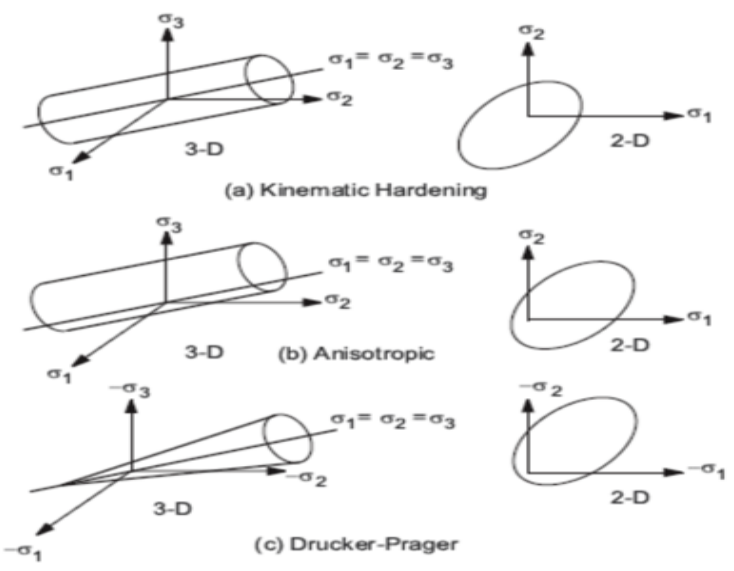

Figure 2. Various yield surfaces [6]

Stresses and strains during material plastic deformation show a dependence on prior loading history. Incremental plasticity model procedure is implemented to identify the dependence through the relation between stress and strain (Matos, 2010). Typical increments of strain are decomposed plastic and elastic strain components.

$$
d \varepsilon=d \varepsilon^{e}+d \varepsilon^{p}
$$

Basan considers it as associative when the plastic potential and yield function are equal $(\mathrm{Q}=\mathrm{F})$. According to Ducker's theory, this is valid equation for stable materials. Adds Ducker, the yield surface is convex and vector of the plastic strain increment on a smooth point of the yield surface which is directed outward of the normal yield surface [6]. He explained differences between associative flow rule and non-associative flow rule in which the plastic potential is not equal to yield function. The difference between associative flow rule and non-associative flow rule is explained in below.

Where

$$
d \varepsilon_{i j}^{p l}=\lambda \frac{\partial Q}{\partial \sigma_{i j}}
$$

$\lambda=\quad$ plastic multiplier

$\mathrm{Q}=\quad$ function of stress termed the plastic potential

\section{Material Hardening and Plasticity of the material}

Linear elasticity is a useful parameter in modelling when deformation in the material has high impact over the specimen under load conditions. Almost, most of the engineering materials have slight permanent deformation on removal of the load.

In deformation there are two variants namely reversible and irreversible. In reversible deformation, on load application the strain energy is stored in the material and a form of deformation is observed. Once the load is removed, the strain energy is released, and material regains its original posture. But in irreversible deformation, the energy is not stored in the material, but it is dissipated causing a change in posture of the material.

Permanent deformation is observed in the material when yield stress is above the critical value. Plastic deformation is observed only beyond yield point while load permanent deformation is observed till the crystal structure of the material is disturbed and migration of the grain at micro level is achieved. However, stress induced in the material is independent of the load applied.
In load condition unidirectional case, material will undergo deformation up to yield point $\mathrm{Y}$ and then undergoes hardening. Figure 3 depicts uni-axial load stress strain curve.

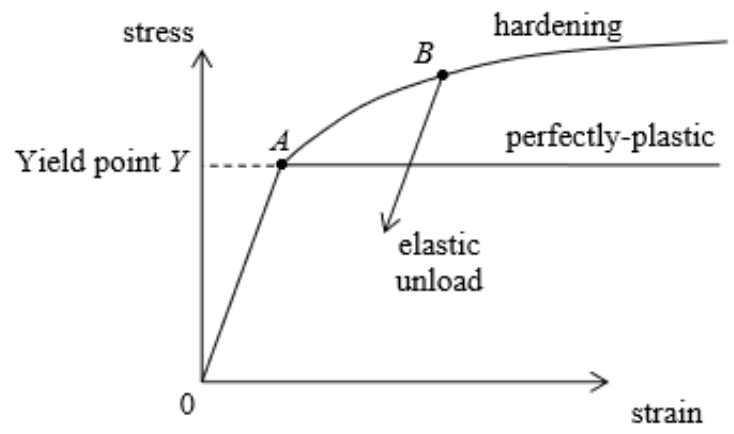

Figure 3. stress stain curve for metal [5]

Once the stress reaches from initial value to point $\mathrm{A}$, specimen is under yield stress. From 0 to point $A$, the specimen is on elastic load and the material can withstand without any permanent deformation. When the stress moves from point $A$ to point $\mathrm{B}$, slight or negligible deformation that is allowable is observed in the material, and from point $B$ onwards perfect plasticity is gained in the material [5]. Material elastic unloading occurs from point B when the stress is reduced. However, loading must be continued to achieve plastic deformation when the material has to be hardened after yield stress.

Robert Basan's hardening rule represents the condition for establishment of subsequent yielding behaviour after the occurrence of initial yielding. According to him, the point of stress space cannot lie outside the yield surface which has to change its size for further yielding to occur [6]. There are two hardening rules namely, Isotropic hardening rule and Kinematic hardening rule.

In Isotropic hardening, the yield stress is maintained equally in compression and tension load condition while in Kinematic hardening, the elastic range is constant throughout deformation. When a sample is under tension load, Bauschinger effect is observed in the material. Bauschinger effect is the variation in the yield stress between the compression and tension load on the sample. When the specimen reaches maximum yield strength under tension load the sample undergoes compression load. At this point, the yield stress observed at the tension load and compression is different. This effect is clearly illustrated in Figure 4. In the Figure, the real material response is depicted in solid line and the extreme cases in plasticity models are expressed in dotted lines.

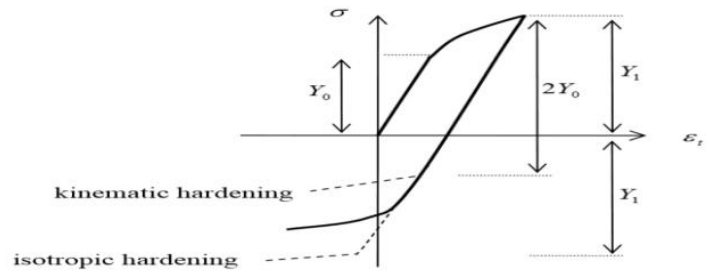

Figure 4. Bauschinger effect [5]

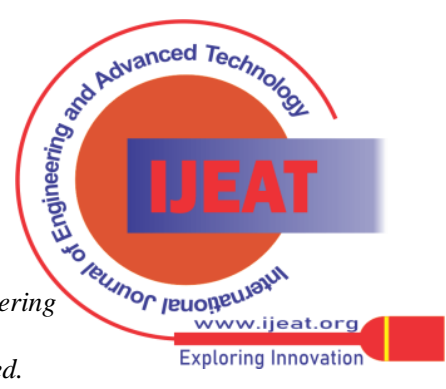




\section{Isotropic Hardening and Kinematic Hardening}

In Isotropic hardening rule, yield surface remains centered about its center line $\left(\sigma_{1}=\sigma_{2}=\sigma_{3}\right)$ in stress space and expands or shrinks in size as plastic strain develops whereas Kinematic hardening rule presumes that the translation of the yield surface through the stress space with progressive yielding result in the yield surface remaining constant in size, Figure 5.

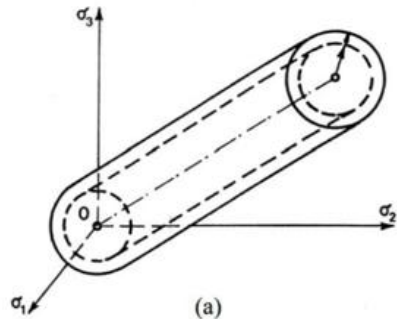

(a)

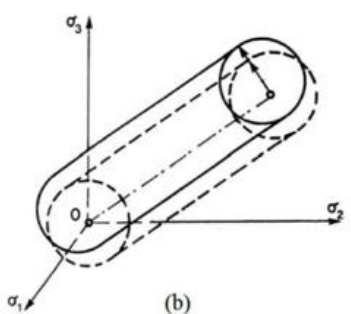

(b)
Figure 5. Types of hardening (a) isotropic hardening (b) kinematic hardening [6]

Zhang stated that the hysteresis loops are independent on the strain amplitude for the strain ranges under cyclic hardening tension compression [7]. The author discussed tension-compression and torsional cyclic loading conditions using the cyclic hardening process. He observed that as the number of cycles increase, hardening of material also increases. He also noticed differences at different strain amplitudes of $1 \%, 0.5 \%$, and $0.2 \%$ in figure 6 .

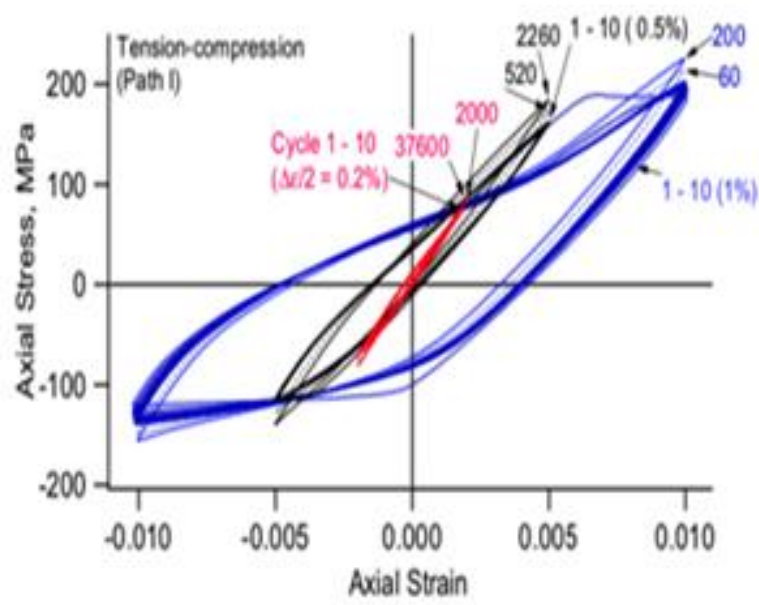

Figure 6. Stress-strain hysteresis loops under fully reversed strain-controlled tension-compression $(\Delta \mathrm{e} / 2=$ $0.2 \%, 0.5 \%$, and $1.0 \%$ ). (Zhang et al., 2011)

According to [3], the plastic strain amplitude increases with change in time and remains constant until the strain increases over the number of cycles (Figure 6). The plastic strain amplitudes are same in all the events. The plastic strain amplitude decreases with strain and then increases with increasing stress. He discussed monotonic curve and half life cycle of magnesium alloy. He also compared monotonic results with cyclic hardening process to determine cyclic loading behaviour and fatigue life.

\section{Material and Material Properties}

In this paper, to study plasticity which is one of the properties of AZ31 type magnesium material, cyclic loading behaviour is applied. The chemical composition of
AZ31type magnesium alloy used in this study is given in table 1.

Table 1. Composition of AZ31 alloy.

\begin{tabular}{|c|c|}
\hline $\mathrm{Al}$ & 3.1 \\
\hline $\mathrm{Zn}$ & 1.2 \\
\hline $\mathrm{Mn}$ & 0.2 \\
\hline $\mathrm{Si}$ & 0.05 \\
\hline $\mathrm{Cu}$ & 0.05 \\
\hline $\mathrm{Ca}$ & 0.04 \\
\hline $\mathrm{Fe}$ & 0.005 \\
\hline $\mathrm{Ni}$ & 0.1 \\
\hline $\mathrm{Other}$ & 0.4 \\
\hline $\mathrm{Mg}$ & Balance \\
\hline
\end{tabular}

The below mentioned material properties were considered for theoretical calculations in table 2 below.

Table 2. Material properties of AZ31 alloy

\begin{tabular}{|c|c|}
\hline Density & $1.77 \mathrm{~g} / \mathrm{cm}^{3}$ \\
\hline Tensile strength & $296 \mathrm{MPa}$ \\
\hline Compressive yield strength & $97 \mathrm{MPa}$ \\
\hline Shear strength & $130 \mathrm{MPa}$ \\
\hline Elastic modulus & $45 \mathrm{GPa}$ \\
\hline Poisson's ratio & 0.32 \\
\hline Elongation at break (50mm) & $15 \%$ \\
\hline Bearing yield strength & $250 \mathrm{MPa}$ \\
\hline
\end{tabular}

Source: https://www.azom.com/article.aspx?ArticleID=6707

Aluminium is the most used material in the aerospace industries and is it used for packing material for food. Also, aluminium is the base material for the versatile paint. High resistance to corrosion is the property that draws automobile attention in selecting material for the interior parts. Low density is the main purpose for using in the structure applications. Strength to weight ratio of the aluminium material is very high and is another reason for selecting material for building the parts for aircraft industries. Cyclic loading is more important parameter for developing parts out of aluminium since the young's modulus is lower and density of the material is low.

\section{METHODOLOGY}

\section{Multi-Linear (Isotropic, Kinematic) Hardening Curve}

In kinematic hardening the yield surface remains constant in size and translates in the direction of yielding. When a load or displacement applied on specimen after attaining plastic deformation, the specimen will not come to its original position due to behaviour of hardening curve.

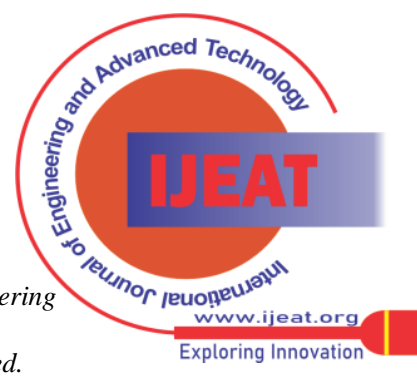


In ANSYS finite element method, to perform multilinear hardening simulation, one must calculate plastic strain and true strain from monotonic tensile test data. As monotonic tensile test data is huge, consider few points to give as an input in software. Required calculations and data is provided in Figure 7.
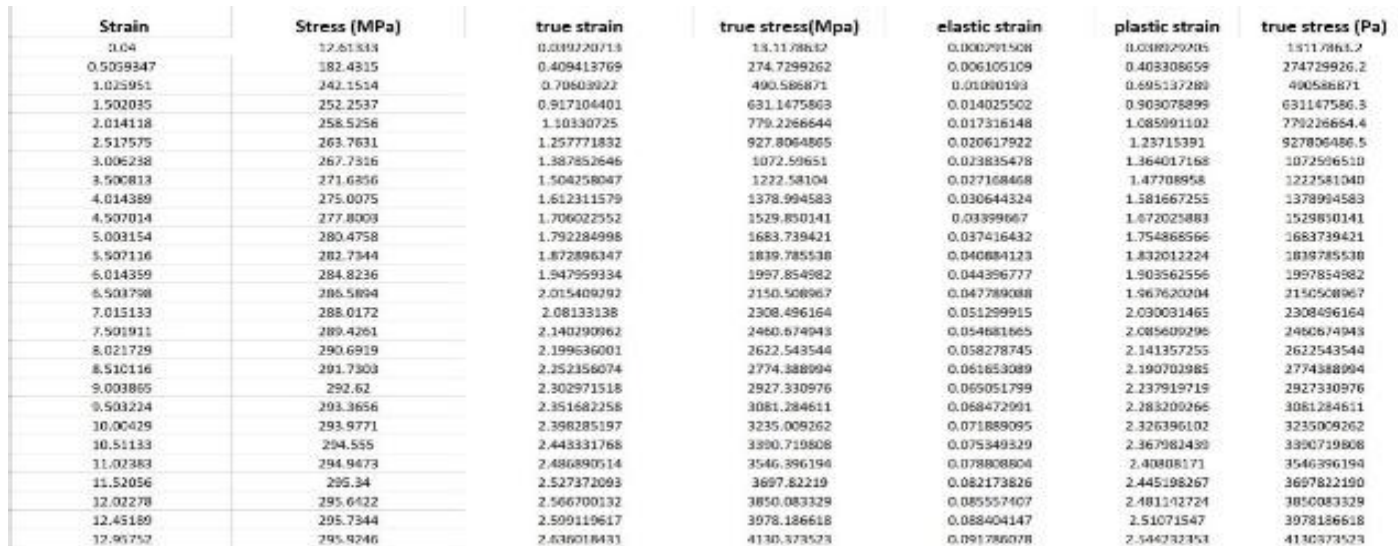

Figure 7. calculation of true stress, elastic strain, and plastic strain.

To input plastic strain and stress in ANSYS initially, true strain and true stress need to be calculated.

True strain $=\ln (1+$ strain $)$

True stress=stress $(1+$ strain $)$

In next step, calculate elastic strain.

elastic strain $=$ (true stress $) / E$

Where E is young's modulus of AZ31 $=45000 \mathrm{MPa}(45 \mathrm{GPa})$

After calculating elastic strain, plastic strain is calculated by subtracting true strain from elastic strain.

Plastic strain=elastic strain-true strain

The above-mentioned calculations are considered from ANSYS student support to derive true stress and plastic strain. https://studentcommunity.ansys.com/thread/Multilinear-kinematic-plasticity-material-model-create-from-astress-strain-graph/?order=all\#comment-e6945286-75dd4163-b6ca-a81c000d4c7a(Dated 18/05/2020)

Plastic strain obtained from above calculation is used to input in simulation to determine plastic strain on AZ31 alloy under cyclic loading behaviour. True stress vs plastic strain and stress vs strain have been plotted to show difference between calculated and practical values.To verify calculated values, a logarithmic graph is plotted between true stress vs plastic strain using points after yield stress to plot a linear line. Above calculated plastic strain is used as an input in ANSYS software to calculate plastic strain acting on AZ31 alloy under cyclic loading behaviour.

\section{Multi-Linear Isotropic Hardening or Multi-Linear Kinematic Hardening Curve}

In ANSYS, to obtain multi-linear hardening (isotropic or kinematic) curves, plastic strain and true stress acting upon specimen need to be determined. Results for this simulation are obtained from monotonic tensile test. As test data is huge, few points are considered to give input to software to get accurate results. Stress and strain points are considered for every $0.05 \mathrm{~mm}$ increase in displacement. The calculations are discussed in mechanical properties in preceding topic.

All inputs to this simulation are in mm and MPa. Plastic strain starts from zero strain and the maximum plastic strain observed is around $2.5 \mathrm{~mm}$ at true stress around $4500 \mathrm{MPa}$. Multi-linear isotropic and Multi-linear kinematic hardening curve looks similar to each other and the input to these two hardening curves are also the same.

In this simulation a specimen of dimensions $3 \mathrm{~mm} * 20 \mathrm{~mm}$ (diameter*length). One end of the specimen is fixed and

Retrieval Number: 100.1/ijeat.E27900610521

DOI:10.35940/ijeat.E2790.0610521

Journal Website: www.ijeat.org other end of specimen a cyclic displacement is applied. From monotonic tensile test huge data few displacement points are considered as input for cyclic loading condition with time as independent variable. Displacement from $1 \mathrm{~mm}$ to $7.5 \mathrm{~mm}$ has been given to cyclic loading condition. Strain has been increased from $0-1 \mathrm{~mm}$ to $1 \mathrm{~mm}$ to 0 , repeat this procedure from $0-2 \mathrm{~mm}$ to $2 \mathrm{~mm}-0$ and continue same procedure up to $7.5 \mathrm{~mm}$ to make input as cyclic loading. The displacement is assigned to specimen by cyclic loading, maximum displacement acting as $7.5 \mathrm{~mm}$ and at final step of this simulation displacement is heading to zero at 466 steps.

\section{RESULTS}

\subsection{Multi-Linear Isotropic Hardening}

\subsubsection{Multi-Linear Isotropic Hardening - 0.4mm Linear Mesh}

The simulation is about plastic strain when multi-linear isotropic hardening property is assigned to AZ31 specimen. While performing simulation, linear and quadratic element with mesh size $0.4 \mathrm{~mm}$ and $0.6 \mathrm{~mm}$ is assigned to the specimen to study cyclic loading behaviour.

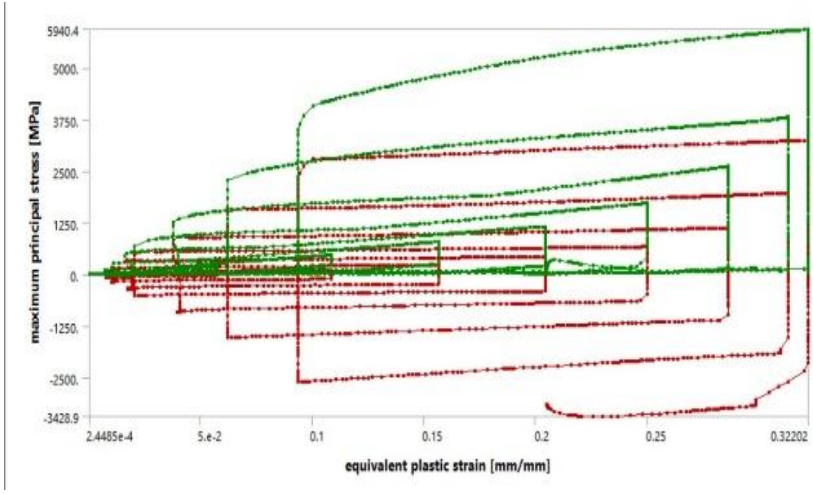

Figure 8. Multi-linear isotropic hardening $-0.4 \mathrm{~mm}$ linear mesh, Maximum principal stress vs Equivalent plastic strain.

Published By:

Blue Eyes Intelligence Engineering and Sciences Publication (C) Copyright: All rights reserved.

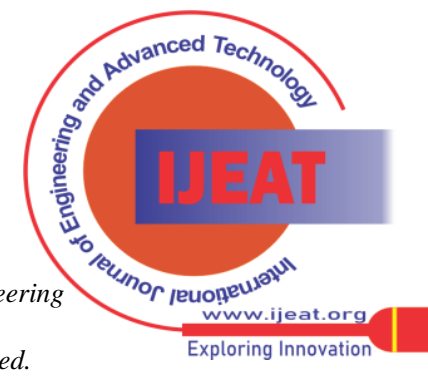


Figure 8 plots maximum principal stress $(\mathrm{MPa})$ vs equivalent plastic strain(mm). The maximum stress observed during last tensile cycle is $5904 \mathrm{MPa}$. The stress difference between 7 th cycle and last cycle is almost $2000 \mathrm{MPa}$. In this plot, the stress increase is not linear and keeps on increasing like loops for every cycle. The maximum equivalent plastic strain acting on AZ31 is around $0.32 \mathrm{~mm}$ during last cycle while in the 7thcycle; the plastic strain is around $0.30 \mathrm{~mm}$. The maximum compression stress acting on AZ31 is around $-3428 \mathrm{MPa}$ by the end of the simulation.

In below Figure 9, the plot is between middle principal stress (MPa) and equivalent plastic strain(mm). The maximum-middle principal stress during last tensile cycle is observed as 4339MPa and maximum-middle principal stress during last compression cycle is noted as -3472MPa. In middle principal stress vs plastic strain plot, we can observe tensile and compression cycles acting on AZ31 clearly whereas in Figure 6 we can observe tensile and compression cycles imposing on each other because of maximum and minimum stress acting on the specimen.

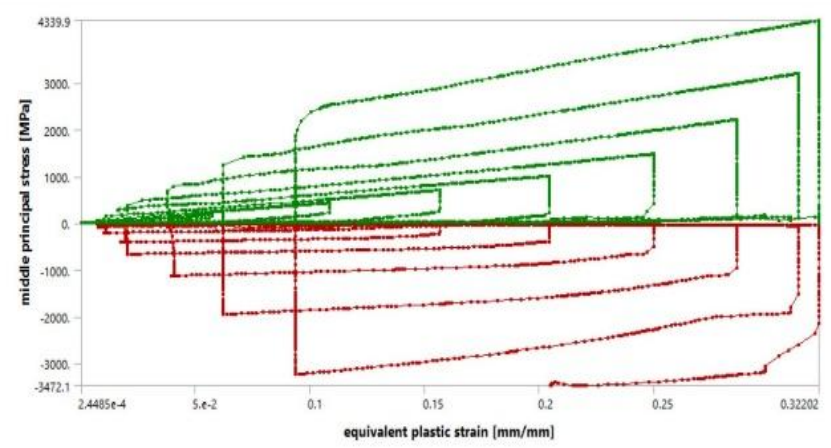

Figure 9. Multi-linear isotropic hardening $-\mathbf{0 . 4 m m}$ linear mesh, Middle principal stress vs Equivalent plastic strain

\subsubsection{Multi-Linear Isotropic Hardening $-\mathbf{0 . 4 m m}$ Quadratic Mesh}

In Figure 10, the plot is between maximum principal stress (MPa) and equivalent plastic strain(mm) acting on AZ31 during cyclic loading behaviour. The maximum stress acting on the specimen during tensile loading is $7113 \mathrm{MPa}$ which is represented using green line. During last three cycles the stress difference between each cycle is around 2000MPa. The red line represents the maximum stress during compression cycle which is around -3200MPa. The equivalent plastic strain during the last compression cycle has become flat and by the end of the simulation it is around $0.21 \mathrm{~mm}$.

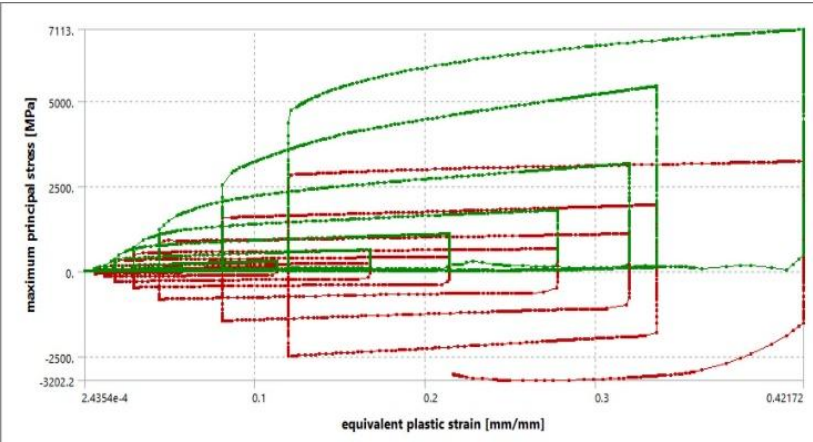

Figure 10. Multi-linear kinematic hardening $-\mathbf{0 . 4 m m}$ quadratic mesh, Maximum principal stress vs Equivalent plastic strain
In below Figure 11, while comparing middle principal stress (MPa) with equivalent plastic strain $(\mathrm{mm})$, the tensile stress during the last cycle is around $3659 \mathrm{MPa}$ and the stress during compression cycle is around $-3650 \mathrm{MPa}$.

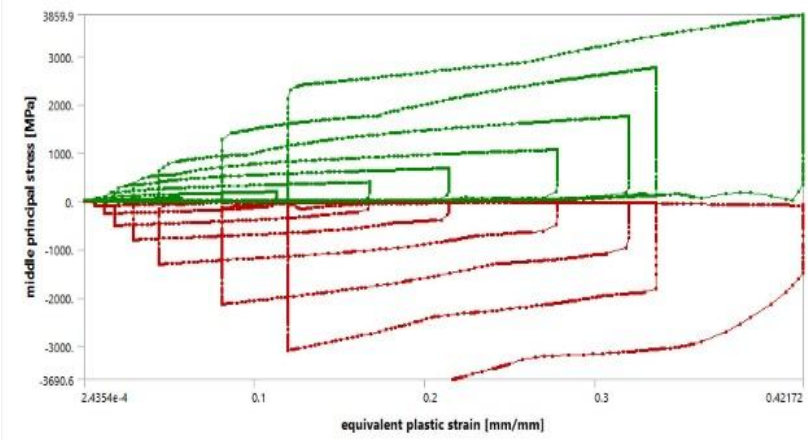

Figure 11. Multi-linear isotropic hardening $-0.4 \mathrm{~mm}$ quadratic mesh, Middle principal stress vs Equivalent plastic strain

\subsubsection{Multi-Linear Isotropic Hardening - 0.6mm Linear Mesh}

In below Figure 12, the plot is between maximum principal stress (MPa) and equivalent plastic strain(mm). In the simulation, the maximum stress acting on the specimen during tensile cycle is $5229 \mathrm{MPa}$ and during compression cycle, the maximum stress is around $-3387 \mathrm{MPa}$ by the end of the simulation. The plastic strain acting on AZ31during the last cycle is $0.3114 \mathrm{~mm}$. During compression cycle, the plastic strain has dropped down to $0.20 \mathrm{~mm}$ and shot up to $0.35 \mathrm{~mm}$ by the end of the simulation.

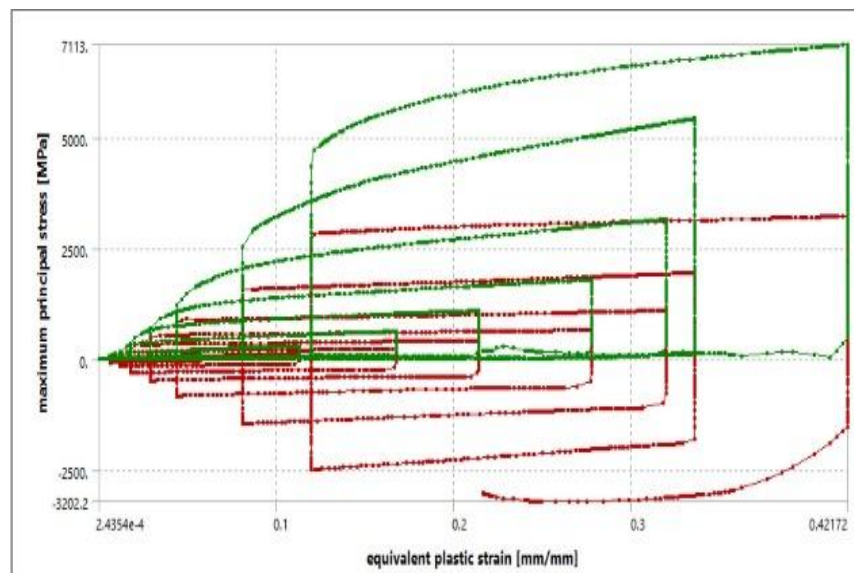

Figure 12. Multi-linear isotropic hardening $-0.6 \mathrm{~mm}$ linear mesh, Maximum principal stress vs Equivalent plastic strain

The below Figure 13 relates middle principal stress (MPa) with equivalent plastic strain (mm). The maximummiddle principal stress during tensile cycle is $3674.8 \mathrm{MPa}$ and maximum-middle principal stress during compression cycle is $-3725.8 \mathrm{MPa}$. The middle principal stress during the first 5 tensile and compression cycles is below 1000MPa.

Published By:

Blue Eyes Intelligence Engineering and Sciences Publication

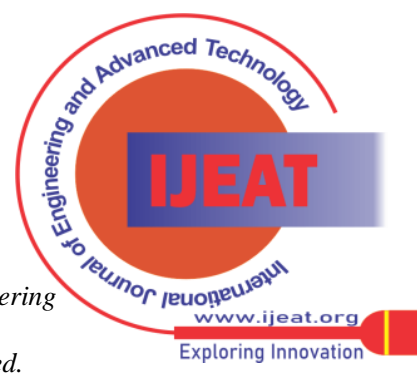




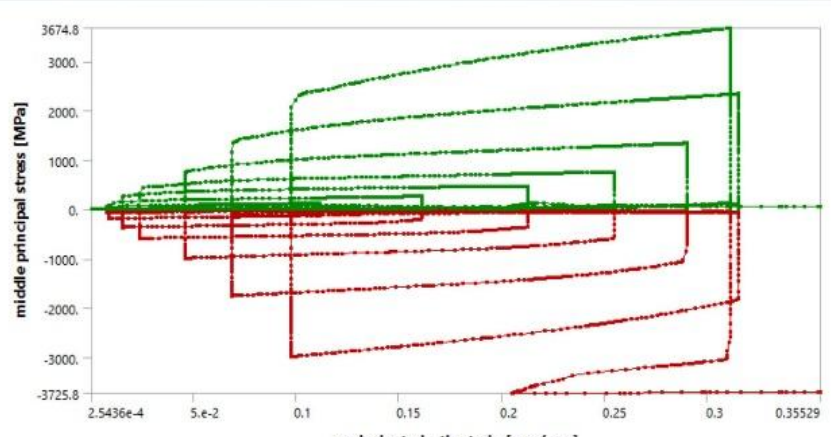

Figure 13. Multi-linear isotropic hardening $-0.6 \mathrm{~mm}$ linear mesh, Middle principal stress vs Equivalent plastic strain

\subsubsection{Multi-Linear Isotropic Hardening - $0.6 \mathrm{~mm}$ Quadratic Mesh}

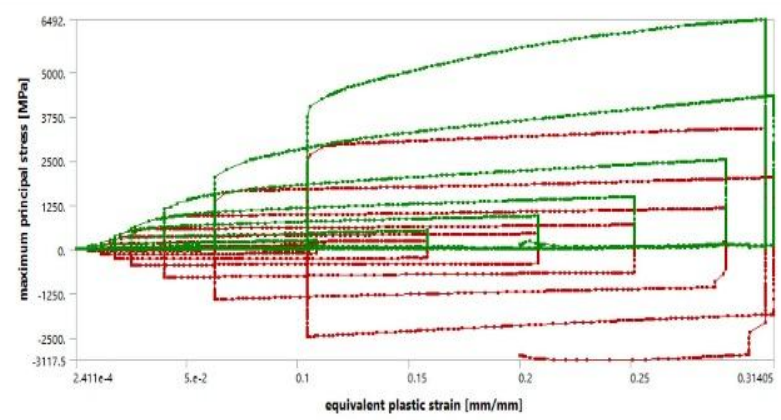

Figure 14. Multi-linear isotropic hardening - 0.6mm quadratic mesh, Maximum principal stress vs Equivalent plastic strain

The above Figure 14 explains maximum principal stress acting on AZ31 during cyclic loading behaviour with displacement as an input to this simulation. The maximum principal stress acting on specimen during tensile cycle is around 6492MPa. The stress difference between last three cycles is around $1500 \mathrm{MPa}$. The maximum equivalent plastic strain acting on the specimen is $0.31 \mathrm{~mm}$ during 8 th cycle and the strain at the end of the simulation is $0.20 \mathrm{~mm}$. Maximum stress acting on AZ31 specimen during compression cycle is around $-3117 \mathrm{MPa}$. The stress during first 5 tensile and compression cycles is less than $1000 \mathrm{MPa}$. In Figure 15, the maximum-middle principal stress acting on specimen during the last cycle is $3142 \mathrm{MPa}$ and the stress during 7th cycle is around 2000MPA with a stress difference of around $1200 \mathrm{MPa}$. The maximum-middle principal stress acting during compression cycle is $-3144 \mathrm{MPa}$ with plastic strain less than the 7 th cycle.

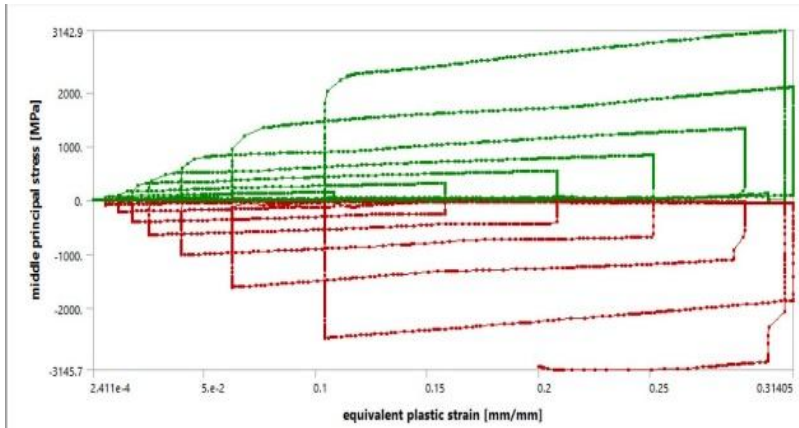

Figure 15. Multi-linear isotropic hardening $-\mathbf{0 . 6} \mathrm{mm}$ linear mesh, Middle principal stress vs Equivalent plastic strain

\subsection{Multi-Linear Kinematic Hardening}

In this simulation the variable parameters are mesh size $0.4 \mathrm{~mm}$ and $0.6 \mathrm{~mm}$ with linear and quadratic element type. The input for the simulation is cyclic displacement up to $7.5 \mathrm{~mm}$. The plot is between equivalent stress and equivalent plastic strain.

\subsubsection{Multi-Linear Kinematic Hardening - 0.4mm Linear Mesh}

The below Figure16 explains plot between equivalent stress (MPa) and equivalent plastic strain(mm). The equivalent stress acting on AZ31 during the last cycle is 277.72MPa. The increase in stress per cycle is around 40MPa. In this simulation, the stress for every cycle is following linear path in continuation of pervious cycle showing that specimen is holding energy and displacement. The maximum plastic strain at the end of the simulation is $0.40 \mathrm{~mm}$.

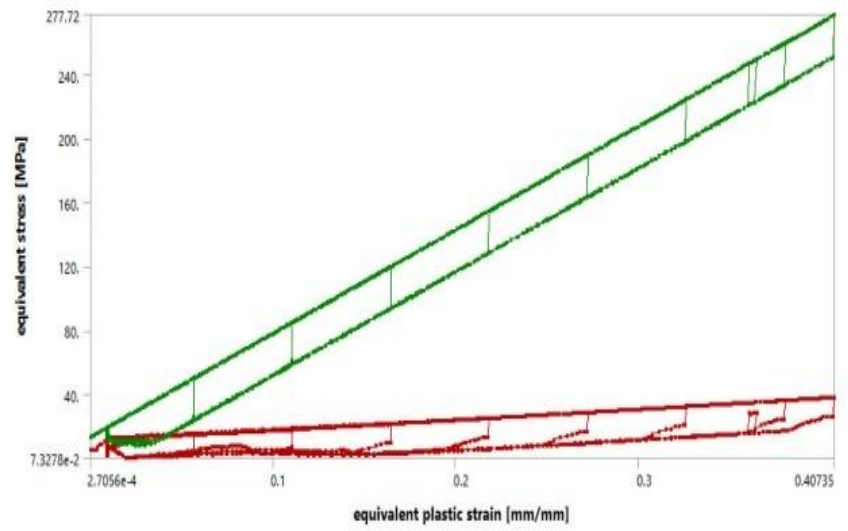

Figure 16. Multi-linear kinematic hardening $-0.4 \mathrm{~mm}$ linear mesh, Equivalent stress vs equivalent plastic strain

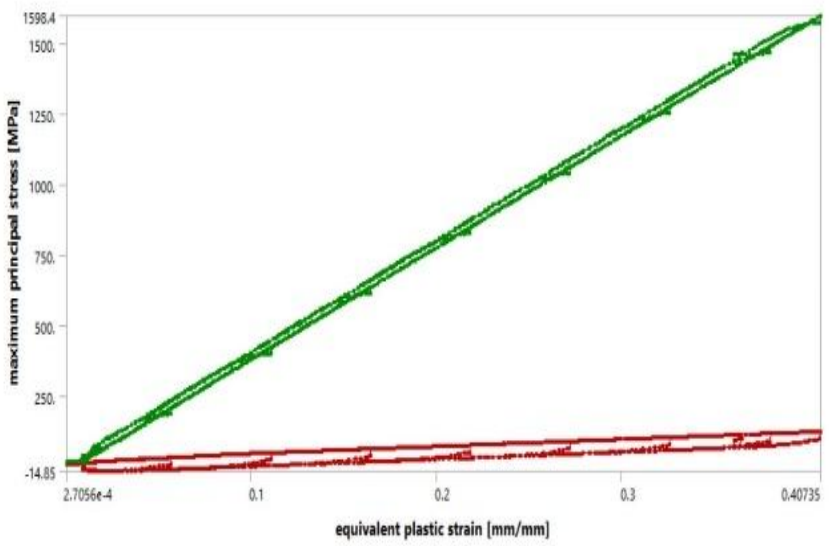

Figure 17. Multi-linear kinematic hardening $-\mathbf{0 . 4 m m}$ linear mesh, Maximum principal stress vs Equivalent plastic strain.

The above Figure 17 explains plot between maximum principal stress $(\mathrm{MPa})$ and equivalent plastic strain $(\mathrm{mm})$. The maximum stress acting on AZ31 during the last cycle is around 1598MPa. The compression cycle can be observed with minimal stress acting on specimen.

Published By:

Blue Eyes Intelligence Engineering and Sciences Publication (C) Copyright: All rights reserved.

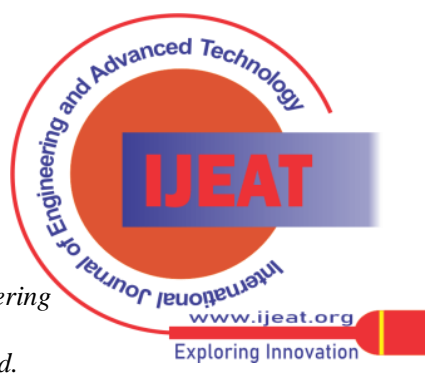


Middle principal stress acting on AZ31 during tensile cycle with maximum stress at around 1520MPa. The stress increase in between cycles beginning with the initial cycle is 250MPa. The equivalent plastic strain acting on AZ31 specimen is $0.407 \mathrm{~mm}$. The increase in plastic strain gets reduced in the last three cycles showing maximum plasticity of specimen.

\subsubsection{Multi-Linear Kinematic Hardening - $0.4 \mathrm{~mm}$ Quadratic Mesh}

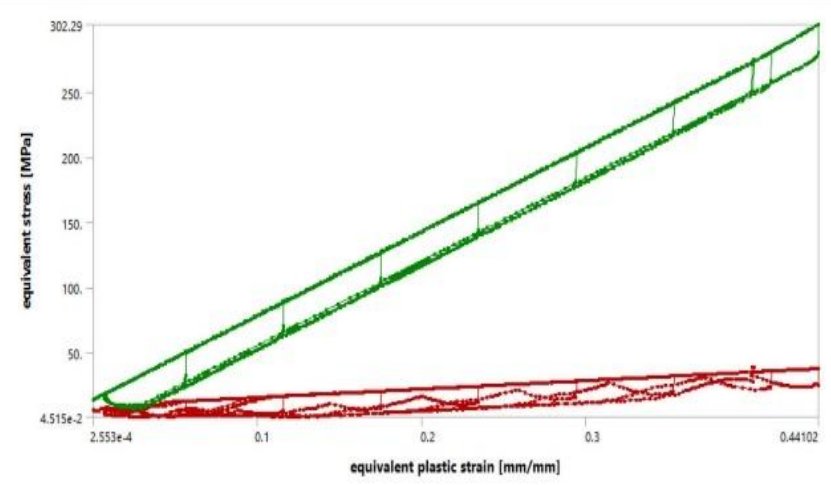

Figure 18. Multi-linear kinematic hardening $-0.4 \mathrm{~mm}$ quadratic mesh, Equivalent stress vs equivalent plastic strain

The above Figure 18 plots equivalent stress (MPa) vs equivalent plastic strain $(\mathrm{mm})$. The equivalent stress acting on the specimen is around $302 \mathrm{MPa}$ during the last tensile cycle. The maximum plastic strain during the last cycle is around $0.44 \mathrm{~mm}$. The increase in stress per cycle is around $50 \mathrm{MPa}$ per cycle.

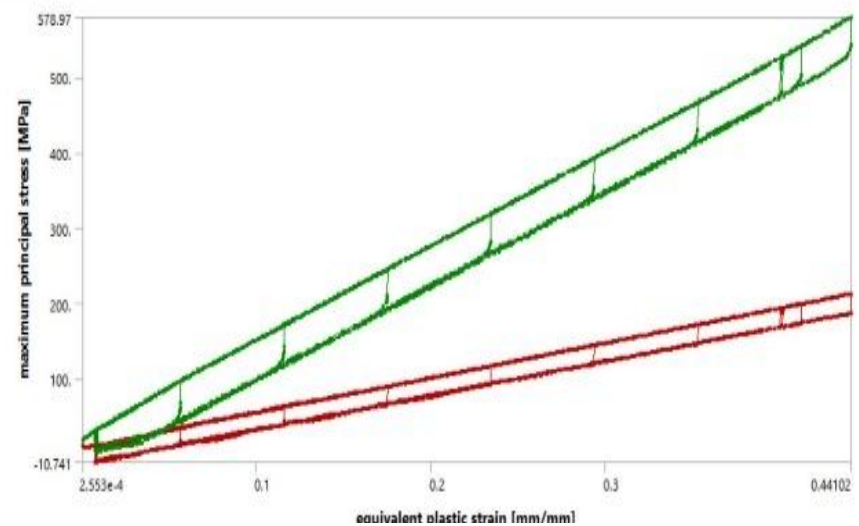

Figure 19. Multi-linear kinematic hardening $-0.4 \mathrm{~mm}$ quadratic mesh, Maximum principal stress vs Equivalent plastic strain

The above plot in Figure 19 is to relate maximum principal stress (MPa) with equivalent plastic strain(mm). The maximum stress observed during this simulation is around $578 \mathrm{MPa}$ and the maximum equivalent strain observed during the last cycle is about $0.44 \mathrm{~mm}$. Middle principal stress (MPa) and equivalent plastic strain(mm). The maximum-middle principal stress acting on AZ31 is 378MPa. The average increase in stress per cycle is around $60 \mathrm{MPa}$.

\subsubsection{Multi-Linear Kinematic Hardening - 0.6mm Linear Mesh}

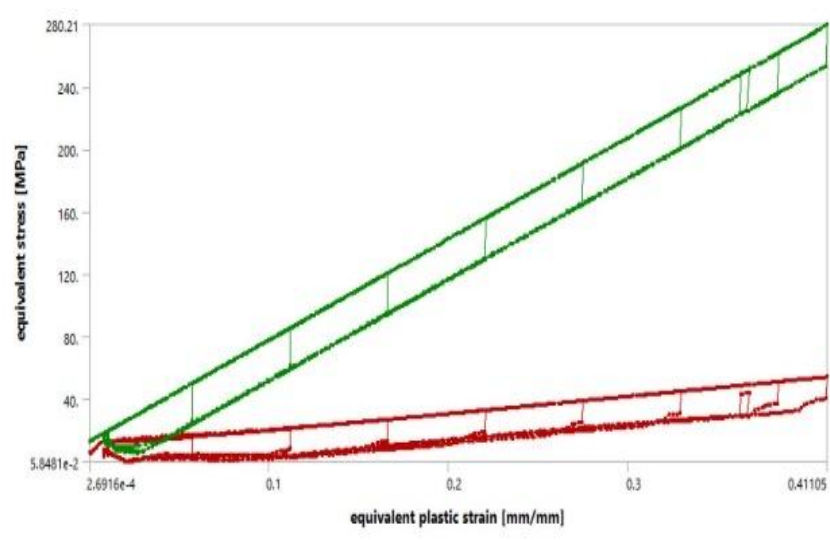

Figure 20. Multi-linear kinematic hardening $-\mathbf{0 . 4 m m}$ linear mesh, Equivalent stress vs Equivalent plastic strain

The above plot 20 is between equivalent stress (MPa) and equivalent plastic strain (mm). The maximum stress acting on specimen during cyclic loading observed is around 280.1MPa. The plot is linear showing specimen holding stress from cycle to cycle after the application of cyclic load. The equivalent plastic strain acting on the specimen is $0.411 \mathrm{~mm}$ during the last cycle.

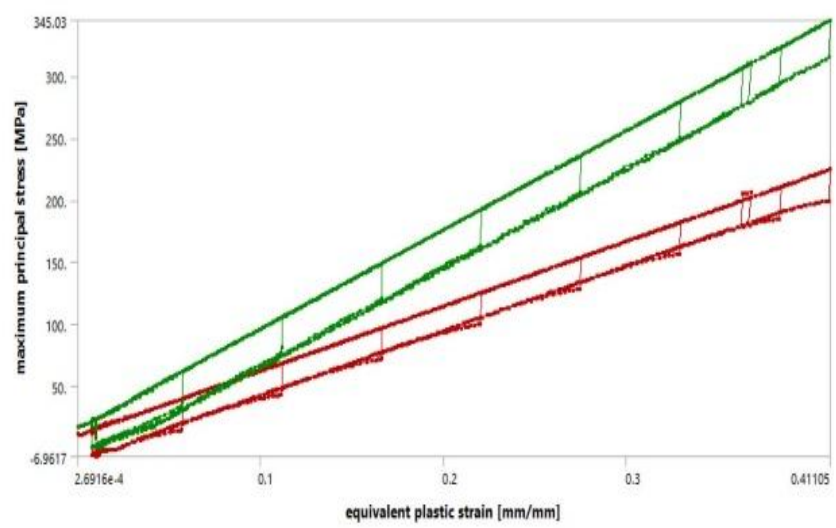

Figure 21. Multi-linear kinematic hardening $-\mathbf{0 . 4 m m}$ linear mesh, Maximum principal stress vs Equivalent plastic strain

The figure 21 explains about maximum principal stress (MPa) vs equivalent plastic strain(mm) acting on AZ31. It is observed that the maximum principal stress acting on specimen is around $345.03 \mathrm{MPa}$ and the equivalent plastic strain at the end of the simulation is around $0.410 \mathrm{~mm}$. The maximum-medium principal stress during tensile cycle on AZ31 is 232MPa. The stress acting on specimen during the second cycle is around $80 \mathrm{MPa}$ with strain $0.11 \mathrm{~mm}$. In this simulation, AZ31 specimen will store energy or displacement after every cycle that leads to lower stress values when compared with multi-linear isotropic hardening curve results.

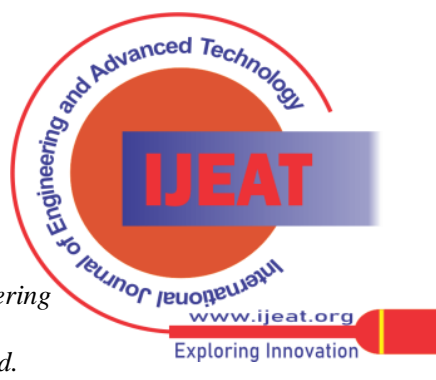




\subsubsection{Multi-Linear Kinematic Hardening - $0.6 \mathrm{~mm}$ Quadratic Mesh}

The Figure 22 explains equivalent stress (MPa) vs equivalent plastic strain $(\mathrm{mm})$ acting on AZ31 specimen. The maximum stress observed during this simulation is 278.4MPa. The equivalent plastic strain observed during the last cycle by the end of the simulation is $0.403 \mathrm{~mm}$.

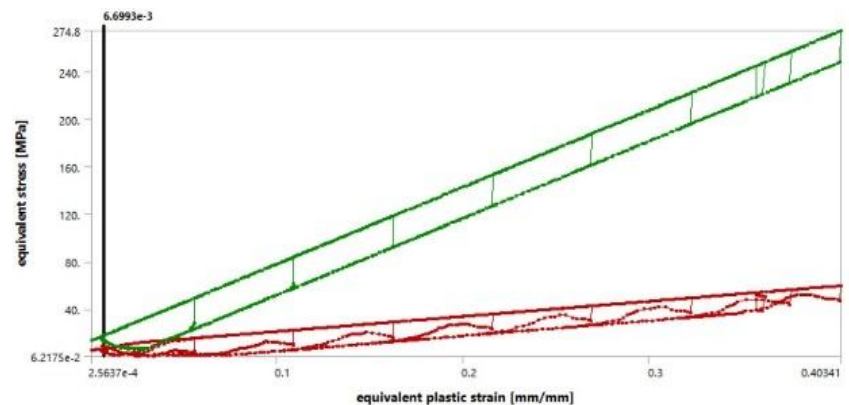

Figure 22. Multi-linear kinematic hardening $-\mathbf{0 . 6 m m}$ quadratic mesh equivalent stress vs Equivalent plastic

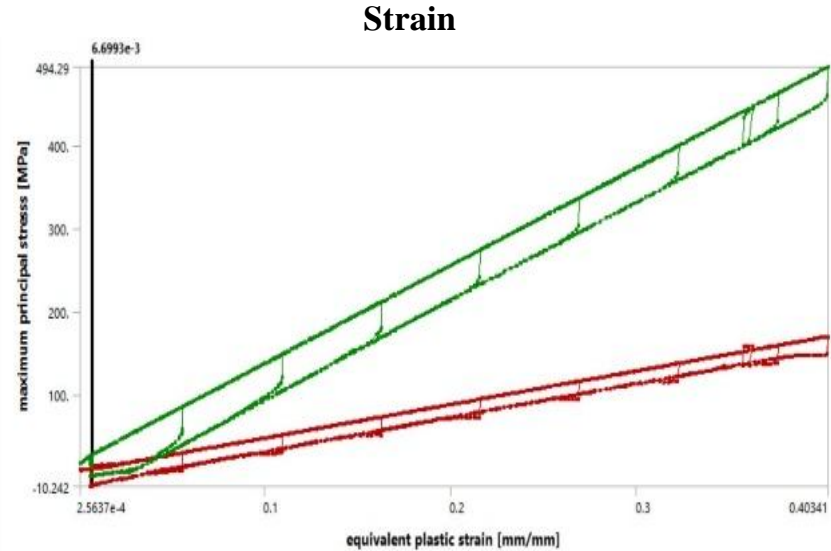

Figure 23. Multi-linear kinematic hardening $-\mathbf{0 . 6 m m}$ quadratic mesh, Maximum principal stress vs Equivalent plastic strain.

The above Figure 23 explains plot between maximum principal stress (MPa) and equivalent plastic strain (mm). The maximum stress observed during the last cycle is 494MPa. The average increase in stress per cycle for the first 6 cycles is around $70 \mathrm{MPa}$ and during the last two cycles a minor change in stress is observed. The middle principal stress is $308 \mathrm{MPa}$ at the end of the simulation.

\section{DISCUSSIONS AND CONCLUSIONS}

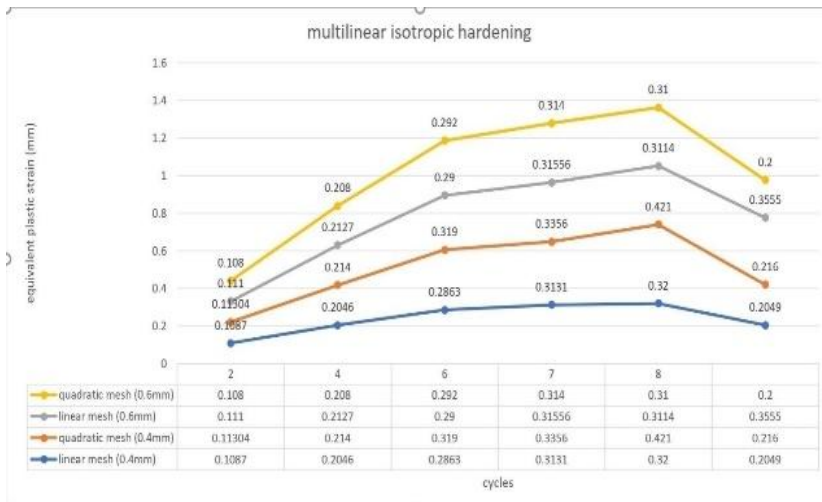

Figure 24. linear and quadratic element type with $0.4 \mathrm{~mm}$ and $0.6 \mathrm{~mm}$ mesh size, multi-linear isotropic hardening
The above Figure 24 explains plot between linear and quadratic element type with $0.4 \mathrm{~mm}$ and $0.6 \mathrm{~mm}$ mesh size when cyclic displacement is acting on AZ31. In this simulation, plastic strain at the end of the simulation did not reach zero but stopped at a point during compression cycle. The maximum equivalent plastic strain during 2nd cycle is $0.1130 \mathrm{~mm}$ in simulation with quadratic element $0.4 \mathrm{~mm}$ mesh size, the minimum equivalent plastic strain observed in both linear and quadratic element type $0.4 \mathrm{~mm}$ and $0.6 \mathrm{~mm}$ linear mesh as $0.108 \mathrm{~mm}$. Maximum plasticity noticed during 4th cycle with quadratic element $0.4 \mathrm{~mm}$ mesh size is $0.212 \mathrm{~mm}$ and with linear mesh $0.6 \mathrm{~mm}$ the plasticity is $0.212 \mathrm{~mm}$. The maximum plastic strain during the 6th cycle is $0.319 \mathrm{~mm}$ with quadratic element $0.6 \mathrm{~mm}$ mesh by the end of the simulation. During 7th cycle, the plastic strain observed is $0.3356 \mathrm{~mm}$ and during the last cycle it shot up to $0.421 \mathrm{~mm}$. At the end of the simulation permanent strain acting on specimen is around $0.216 \mathrm{~mm}$, the minimum plasticity in linear element $0.4 \mathrm{~mm}$ mesh during 4 th cycle is $0.204 \mathrm{~mm}$, during6th cycle is $0.2863 \mathrm{~mm}$ and $0.3131 \mathrm{~mm}$ during 7 th cycle. At the end of the simulation plasticity is $0.2049 \mathrm{~mm}$ for linear element $0.6 \mathrm{~mm}$ mesh. Maximum plasticity noticed is $0.3555 \mathrm{~mm}$ and with minimum value of $0.20 \mathrm{~mm}$ for quadratic element $0.6 \mathrm{~mm}$ mesh. The minimum plasticity during last cycle observed is $0.31 \mathrm{~mm}$.

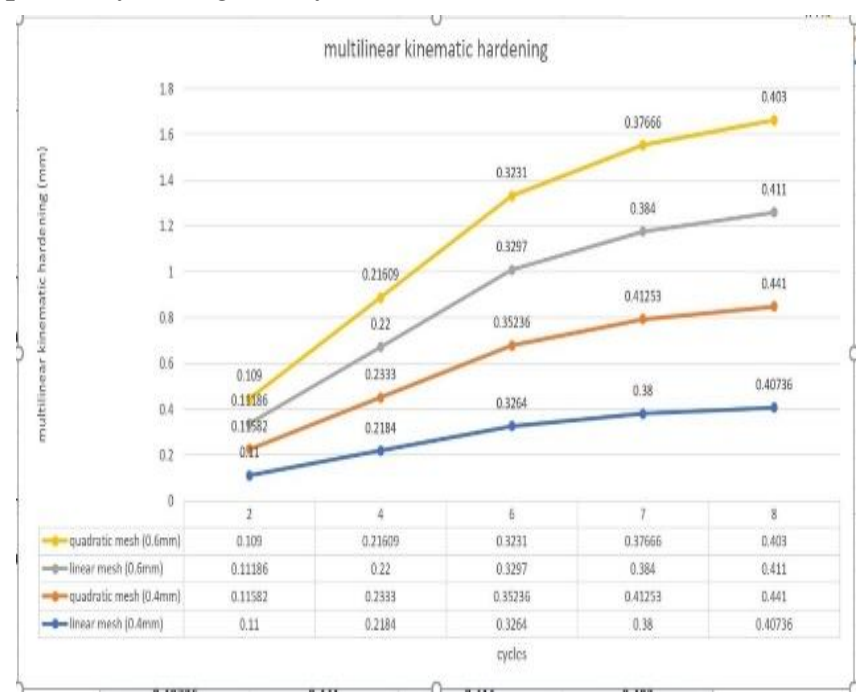

Figure 25. Explains plasticity acting on AZ31 during cyclicloading using multi-linear kinematic hardening

The above Figure 25 explains plasticity acting on AZ31 during cyclic loading using multi-linear kinematic hardening property with linear and quadratic element $0.4 \mathrm{~mm}$ and $0.6 \mathrm{~mm}$ mesh. In this Figure, plastic strain from 2nd cycle to last cycle is observed wherein maximum plastic strain observed on specimen during 2nd cycle is $0.115 \mathrm{~mm}$ in quadratic element $0.4 \mathrm{~mm}$ mesh. The minimum plasticity can be noticed in quadratic element $0.6 \mathrm{~mm}$ mesh as $0.109 \mathrm{~mm}$. During 4th cycle, minimum plasticity with a strain of $0.316 \mathrm{~mm}$ is observed in two simulations with linear element $0.4 \mathrm{~mm}$ mesh and quadratic element $0.6 \mathrm{~mm}$ mesh.

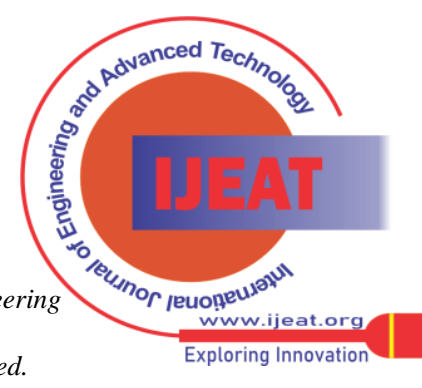


Maximum plasticity during 6th cycle under quadratic element $0.4 \mathrm{~mm}$ mesh is $0.3523 \mathrm{~mm}$, and minimum plasticity during 6th cycle is $0.323 \mathrm{~mm}$ with quadratic element $0.6 \mathrm{~mm}$ mesh. The maximum plastic strain can be observed till the end of the simulation in quadratic element $0.4 \mathrm{~mm}$ mesh. The strain observed during 7 th cycle $0.41253 \mathrm{~mm}$ and during 8 th cycle the strain is $0.441 \mathrm{~mm}$. The lowest plastic strain at the end of the last cycle is $0.403 \mathrm{~mm}$ for quadratic element linear mesh simulation.From above two Figures, maximum plasticity can be noticed in quadratic element $0.4 \mathrm{~mm}$ linear meshing multi-linear isotropic hardening simulation and the maximum plasticity acting on AZ31 is $0.421 \mathrm{~mm}$ and $0.441 \mathrm{~mm}$ for multi-linear kinematic hardening simulation. In all the 16 simulations conducted till the end of the experiment, the maximum plastic strain $0.4425 \mathrm{~mm}$ is observed in bilinear kinematic hardening $0.4 \mathrm{~mm}$ mesh with linear element.On arriving to the conclusion of this paper, the objective of the project is achieved which help of the technological assistants. Comparing the isotropic and kinematic hardening for the magnesium alloy with linear and quadratic mesh was carried out successful. The future scope of this project would help in the application of magnesium alloy in aviation and the other automobile manufacturing.The future scope of work, we have noticed cyclic hysteresis loops for multilinear isotropic hardening curve whereas for multi-linear kinematic hardening curve have observed overlapped loops in the positive quadrant. Change in displacement both positive and negative may result to have better results

\section{REFERENCES}

1. Stutz, L., Bohlen, J., Letzig, D., \&Kainer, K. U. (2011). Formability of magnesium sheet ZE10 and AZ31 with respect to initial texture. In Magnesium Technology 2011 (pp. 373-378): Springer.

2. Masoumi, M., \&Pekguleryuz, M. (2011). The influence of Sr on the microstructure and texture evolution of rolled $\mathrm{Mg}-1 \% \mathrm{Zn}$ alloy. Materials Science and Engineering: A, 529, 207-214.

3. Albinmousa, J., Jahed, H., \& Lambert, S. (2011). Cyclic axial and cyclic torsional behaviour of extruded AZ31B magnesium alloy. International Journal of Fatigue, 33(11), 1403-1416.

4. Anes, V., Reis, L., Li, B. L., \& Freitas, M. Multiaxial Fatigue Behaviour (HCF and LCF) of AZ31 Magnesium Alloy.

5. Kelly, P. (2013). Solid Mechanics. Part II, Lecture notes, The University of Auckland.

6. (Robert Basan,2016) http://www.riteh.uniri.hr/media/filer_public/c7/b4/c7b4b975-94744b66-a04f-

ff3597ba61e7/d711 constitutive modeling and material behavior int erim report.pdf (06/09/2020)

7. Zhang, J., Yu, Q., Jiang, Y., \& Li, Q. (2011). An experimental study of cyclic deformation of extruded AZ61A magnesium alloy. International Journal of Plasticity, 27(5), 768-787.

8. Callister, W. D., \&Rethwisch, D. G. (2007). Materials science and engineering: an introduction (Vol. 7): John wiley\& sons New York.

9. Matos, A. (2010). Multiaxial Fatigue Simulation of an AZ31 Magnesium Alloy using ANSYS and a Plasticity Program.

10. Stutz, L., Bohlen, J., Letzig, D., \&Kainer, K. U. (2011). Formability of magnesium sheet ZE10 and AZ31 with respect to initial texture. In Magnesium Technology 2011 (pp. 373-378): Springer.

\section{AUTHORS PROFILE}

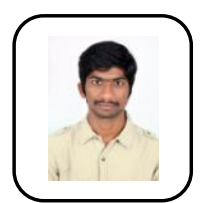

Venkata Sai Prashanth Sudula, pursued master's in mechanical engineering at Federation University Australia. Pursuing MBA- Aviation Management and PGP - Logistics and supply chain management.Design and Development of micro controller drone for civil application, Thermo -Structural analysis in expansion joints on liner and non-liner bellowand bilinear isotropic andbilinear kinematic hardening of AZ31 Magnesium Alloy. Engineers Australia - E grad member.

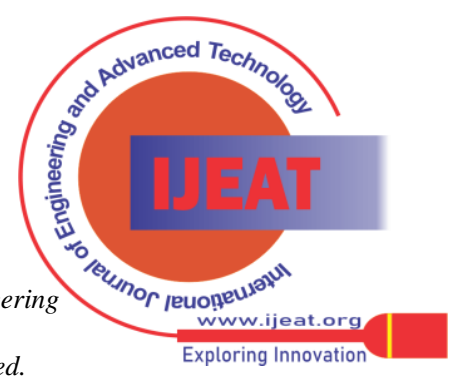

